\title{
Taking the Voluntary Service System as the Starting Point to Explore the Transformation of the Cultivation Mode of Joining the Party -- Take the School of Journalism and Communication of Jiangxi Normal University as an example
}

\author{
Liu Kaiyuan 1, a , Yu Xiangyu 2,b,* \\ ${ }^{1}$ School of Journalism and Communication, Jiangxi Normal University, Nanchang, Jiangxi, China \\ 2 School of Journalism and Communication, Jiangxi Normal University, Nanchang, Jiangxi, China \\ a594627603@qq.com, b1036347422@qq.com \\ ${ }^{*} Y u$ Xiangyu
}

Keywords: Volunteer service; joining the Party; cultivation mode.

\begin{abstract}
Probing into an innovative way in the cultivation and training work for the active college students who are applying for the Party Membership and that is one of the most crucial mission for universities and college Party organizations in the new era.This essay analyzes the advancing experience of party organization in School of Journalism and Communication of Jiangxi Normal University and their innovation in efficient operational mechanisms for training the active applicants .These efficient measures consist of the mechanism of the applicants' voluntary service work and the performance assessment mode for the active applicants. The thesis also attaches a great importance into cultivating a brand-new team of activists who are qualified with the thought of serving the people and the party's Political Ideology .
\end{abstract}

\section{以志愿服务制度为抓手, 探索入党培育模式的转变 一一江西师范大学新闻与传播学院为例}

\author{
刘开源 $1, a$, 余向屿 $2, b,{ }^{*}$ \\ 1江西师范大学新闻与传播学院, 南昌, 江西, 中国 \\ 2江西师范大学新闻与传播学院, 南昌, 江西, 中国 \\ a594627603@qq.com, b1036347422@qq.com \\ *余向屿
}

关键词：志愿服务; 入党; 培育模式

中文摘要. 探索入党培育模式的转变, 把握好大学生入党的培养工作是发展学生党员的基础, 是当代高校党组织的重要任务之一。本文介绍了江西师范大学新闻与传播学院如何积极探索 入党培育模式, 将志愿服务制度与入党积极分子培养考察工作相结合, 从实践中培育注重政 治思想及为人民服务意识的入党积极分子队伍。 


\section{1. 引言}

大学生是国家的希望, 民族的未来。因此, 在大学生群体中开展党员培育工作具有重要 意义。推荐优秀团员做党的发展对象, 是党赋予共青团组织的一项光荣任务, 同时也是团章 所规定的基层团组织任务之一。江西师范大学新闻与传播学院近年积极在入党积极分子中开 展志愿服务工作, 并在志愿者队伍中挖掘思想先进分子, 结合社会实践工作来提高入党积极 分子思想觉悟，培育入党发展对象，在入党培育模式方面取得良好效果。

\section{2. 切入志愿服务制度的意义}

青年志愿工作在党的关怀下，在继承中华民族传统美德的基础上逐步发展。以往评定入 党积极分子, 通常是以学生专业成绩为标准, 再由班级民主投票或由辅导员直接敲定选出有 资格入党的学生。由于评选标准单一, 所入选的大部分学生往往是随大流入党, 入党动机通 常带有功利色彩, 例如以成为一名共产党员来满足自己的虚荣心, 对党的认知不够清晰。志 愿服务制度的切入, 切实将党的全心全意为人民服务的宗旨融入大学生志愿服务活动中, 将 党的为人民服务的义务性与大学生志愿服务的自愿性、导向性结合起来。广泛开展青年志愿 者活动, 不仅成为增强大学生入党积极分子道德意识、社会责任感和奉献精神的有效载体, 也成为党组织考验入党积极分子的有效抓手之一 [1]。江西师范大学新闻与传播学院将志愿服 务制度与入党评定过程结合起来, 有效提高当代大学生的思想境界, 促进学生理解人生价值 在于奉献，真正从实践出发学习党的宗旨与原则，从而成为一名合格的共产党员。

\section{3. 学院党建工作过去不足之处}

\section{1活动开展形式单一}

过去学院各学生党支部开展的教育活动较为单调, 通常多为讲座、报告会等会议形式的 学习与说教, 内容相对枯燥, 形式缺乏新意, 教育效果不明显, 与生活实际脱节。而对学生 党员的考核方式, 偏重思想理论教育, 以笔试党课考试为依据, 使得部分学生党员空有思想 理论却缺乏实际经验，学生党员质量参差不齐，其先锋模范作用发挥不强 ${ }^{[2]}$ 。

\section{2学生党员未充分发挥模范作用}

确定评选入党积极分子时通常为学业成绩优异, 在班级和各类学生工作中表现突出的优 秀学生。但在实际的党课教育实践过程中, 学生党员的教育和管理相对薄弱 ${ }^{[3]}$, 在平时生活 和工作中, 有的学生党员未能以共产党员的标准严格要求自己, 空有头衔而未能发挥好自己 的先锋模范作用。

\section{4. 探索入党培育模式的具体做法}

江西师范大学新闻与传播学院团委学生会志愿者部门和院党员服务站联合每周六组织志 愿者前往南昌绿康养老院、福利院等场所进行志愿服务, 以定期的志愿服务模式嵌入学生入 党积培育过程。服务期间, 由党员服务站专人组织记录志愿者服务工时与服务表现, 并将其 纳入入党考核标准。

\section{1提交入党申请书默认加入志愿者队伍}

在学生提交入党申请书后, 即默认编制进入院志愿者队伍。提倡 “入党先入队”，把参 与志愿者工作作为一项具体考核标准, 对不参与志愿工作以及服务工时、服务表现不合格的 学生取消入党积极分子的评选。在实践初期从群众基础、个人思想品德、志愿服务执行力等 多方面考察学生入党动机, 审核其政治信仰是否坚定。 


\section{2严格考核志愿服务制度}

江西师范大学新闻与传播学院各党支部严格遵循《中国共产党发展党员工作细则》，以 系统规范的管理方式, 使入党积极分子的培养工作愈发科学合理。党支部还以年级为点进行 管理, 对各个年级入党申请档案分类汇总, 定期地对入党积极分子的思想表现、学业成绩、 工作业绩、群众基础等方面进行全面检查, 确保党员的严格性。在此基础上, 为每一位投身 志愿工作的学生建立个人志愿服务档案, 由党支部统一审核进行登记, 对志愿队成员的服务 工时进行记录，并以小组考核形式，由志愿队小组内部成员进行相互评定打分，对服务期间 表现进行评价, 最后在党支部例会上以文件形式进行公示。达到相应考核标准的志愿者方可 参加入党积极分子的评定, 对志愿者服务考核评价不合格的志愿者, 取消入党积极分子评定 资格, 并不得参与第二年入党积极分子的民主评定。在已被推选为入党积极分子后仍要参与 志愿服务, 未达到要求的学生取消党课考试资格, 推迟入党。

\section{3规定志愿服务活动的内容及时间}

不同入党阶段制定不同的志愿服务标准 ${ }^{[4]}$ 。在入党积极分子的培养教育和预备党员的教 育考察时期, 要求预入党积极分子和入党积极分子每学期不少于 20 小时的志愿服务时间, 预 备党员每学期不少于 25 小时的志愿服务时间。分校内校外两线同时进行, 在校内开展环境保 护、教室清洁、图书馆书本维护等工作, 在校外开展偏远学校支教、走进乡村社区服务当地 群众、协助交通出行等志愿活动。

\section{4导师定期召开例会进行沟通指导}

在志愿者进入入党积极分子队伍后, 原则上, 每个月定期召开一次入党积极分子主题工 作大会。鼓励入党积极分子在大会上主动发表当月志愿服务心得体会, 交流平时学习生活、 学生工作等情况, 展开多方互动, 促进相互提升。入党积极分子在自身志愿服务档案上, 自 行对个人优缺点进行评价, 记录自我反省, 再由相应导师给出书面意见, 并当面进行指导。 以长期指导的方式, 对入党积极分子进行思想及综合素质上的督促教育, 引导学生朝良性方 向发展。

\section{5对接志愿服务基地，配合百村调查实践模式}

为切实落实志愿工作, 便于管理志愿者, 保障出行安全, 以免服务工作流于形式, 新闻 与传播学院党支部在学校开展校内志愿服务工作的同时, 积极扩展校外志愿服务渠道, 对接 志愿服务基地开展合作。暑期积极组织3支队伍参与社会实践, 前往安徽东至县、瑞昌市南阳 乡、南昌绿康国际养老城等定点进行志愿实践工作。以服务队为点, 开展形式多样的志愿工 作，如在养老院陪老人、去贫困县走访贫困户、协助扶贫干部进行精准扶贫工作、前往乡村 实地调研等, 从脚踏实地的实践中提高入党积极分子的政治素养及思想觉悟。另外, 结合新 闻与传播学院开展的在华夏田野上进行国情教育的实践育人新模式, 入党积极分子还通过科 学调研、拍摄纪录片、写人物专访及深度报道来深入了解社会、认识国情省情, 以此来加深 与人民群众的感情。

\section{6进行党员和群众民主评议}

每学期党课培训结束后, 由党支部组织入党积极分子和预备党员召开民主评议会, 在大 会上听取入党积极分子和预备党员本学期的志愿服务自我评价。另外, 以问卷调查及各班走 访形式, 收集部分党员及群众意见, 切实了解入党积极分和预备党员平时工作作风及服务表 现，将其作为是否转为预备党员或正式党员的重要依据。 


\section{5.创新入党模式下的影响}

\section{1提高了入党积极分子综合素质}

以志愿服务制度为抓手探索的入党培育模式, 充分提高了入党积极分子队伍质量, 加强 了对入党积极分子培养的全过程管理。从新生一入学就参加志愿服务工作起, 学生在服务工 作过程中懂得感恩, 尊重他人, 提高了个人精神境界。在前往瑞昌市南阳乡实践过程中, 志 愿服务队结合专业特色, 拍摄纪录片等影像作品来配合当地荷花节宣传, 在协助荷花节顺利 开展的同时, 在实践中巩固和提高了自身专业能力, 还发现了自己知识和能力结构上的缺陷, 助其自觉去不断追求新知与科学精神。

学生党员也更加积极主动的去学习专业知识及其他技能, 在实现个人价值的过程中理解 社会价值, 创造社会价值, 对党的认识逐渐深入, 明白了学生党员要抱有服务社会、服务人 民的意识, 从而入党动机也相对更为先进纯洁。入党积极分子为其他同学树立了先锋模范, 使得党员这一形象在学生之间更加光辉起来。同时, 学生在实践过程中深入理解党为人民服 务的宗旨及对人民负责的原则, 其爱国主义思想、自身社会责任感与为人民服务的意识也不 断增强。

\section{2 激发了新闻与传播学院党支部的能量和活力}

志愿者服务制度的切入为推动高校学生党建工作发展提供了一种全新有效的机制和方式 ${ }^{[5]}$ 。党支部开展的各项活动得到了群众的拥护, 在校园和社会上形成强大的感召力。在志愿 者服务工作的影响和带动下, 学院新确定的入党积极分子们不仅在各种公益类活动中表现优 秀, 而且还在班风学风建设、学生工作、各类学术科技竞赛中展露头角。党支部开展的各项 活动, 以入党积极分子为代表积极参与, 营造了积极活跃、你追我赶的学院氛围。同时, 新 闻与传播学院党支各部充分学习贯彻十九大精神, 大胆组织开展丰富多彩、形式新颖的党员 教育实践活动, 增强党组织在高校学生中的吸引力, 增强学生党员教育的实际效果, 为学校 学生党建工作带来新的能量与活力。

\section{3 青年志愿服务活动蓬勃发展}

在入党积极分子投身社会志愿服务的过程中，青年志愿者队伍团队不断扩大，各类志愿 活动组织形式多样, 内容丰富, 服务效果显著, 受到校级志愿组织及社会服务基地的认可。 学院以每周一次志愿活动为期, 广泛吸收入党积极分子参与志愿活动。服务期间, 入党积极 分子主动带头参与志愿服务活动, 发挥自身先锋模范作用, 积极传播青年志愿者奉献理念, 努力为志愿服务事业而奋斗，促进了青年志愿活动的蓬勃发展 ${ }^{[6]}$ 。

\section{6. 结束语}

江西师范大学新闻与传播学院党支部大胆创新, 以志愿服务制度为抓手，探索入党培育 模式的转变, 二者的融合既是推动学生党建工作发展的一个重要手段, 也为当代大学生走进 社会、为今后成为国家栋梁打下铺垫。广大入党积极分子和学生党员通过定期参与志愿服务 工作, 增进了对社会主义核心价值体系和中华民族优秀传统美德的理解和认同, 同时也学会 了帮助他人、回报社会, 在服务他人的过程中提升自身境界, 增强了为人民服务的党员意识。 这一模式的转变, 势必助力高校学生党建工作获得新发展。

\section{致谢}

本文为江西师范大学2018年新闻与传播学院教学建设专题项目《创新志愿服务制度，探 索入党培育模式》和2018年江西省学位与研究生教育教学改革研究项目《“互联网+” 时代 “五 位一体”研究生党建工作模式的研究与实践》阶段性成果之一。 


\section{References}

[1] [6] Xiao Guofeng, Wang Yicheng. Exploration on the Investigation Mechanism of "Volunteer Program" for Activists of the Party in Colleges and Universities: Take Accounting College of Jiujiang University as an example. Literary World of the Party History, 2014 (22): 60-61.

[2] [3] [5] Ma Jie, Guo Lingling. The relationship between youth volunteer service and college students' Party building work[J]. Journal of Hebei Institute of socialism, 2012 (02): 53-55.

[4] Liu Lisi, Jin Minhua. On the Management Mechanism of Voluntary Activities of Party Members in Colleges and Universities: Take the Foreign Language College of China Jiliang University as an example. [J]. Science, Education, Literature and Culture Collection (first ten days), 2014 (04): 181-182. 